\title{
First Steps in Developing an Online Learning Community to Facilitate Knowledge-Sharing on Early Literacy Issues
}

\author{
Tracy Penny-Light \\ Kathleen Bloom \\ Dawn Buzza \\ Barbara Jane Collins \\ Beatrice Moos \\ Judy Carey
}

Acknowledgements: This project was conducted by ResearchWorks! for child literacy, a Community University Research Alliance [CURA] funded by the Social Sciences and Humanities Research Council of Canada.

Correspondence regarding this submission should be directed to:

Dawn C. Buzza

Centre for Learning \& Teaching through Technology (LT3)

329 Dana Porter Library

University of Waterloo

200 University Avenue West

Waterloo, ON N2L 3G1

(519) 888-4567 Ext 3898

dawn@1t3.uwaterloo.ca 


\section{]First Steps in Developing an Online Learning Community to Facilitate Knowledge-Sharing on Early Literacy Issues}

\section{Introduction and Background}

Literacy skills are indisputable keys to academic, employment, health, and social wellbeing. Literacy skills emerge from pre-reading activities in early childhood, activities that help children learn that letters are related to sounds, sounds to words, and that rhymes, songs, and stories can be discovered in print. The importance of providing young children with opportunities for learning about reading is reflected in private and governmental early literacy initiatives. They include programs that provide book gifts to newborns and toddlers, child development resource centres, library programs for infants and pre-schoolers, development of learning materials for child care centres and preschools, and public service announcements. The hope is that families, teachers, librarians, volunteers, and researchers can together, through the exchange of formal and informal knowledge, pave the young child's route to good reading. In a sense, early literacy development can be thought to rest on the maxim: it takes a village to raise a child. The present study explored ways in which members of the child's pre-reading environment can share their knowledge.

The idea for an online forum involving community members in discussion with university students was initially developed out of a desire to enrich the experience of students in an upper-level undergraduate Psychology course focusing on early child 
development. By bringing together students and community members with a shared interest in early literacy issues, we hoped to facilitate knowledge sharing and learning for both groups. In particular, we saw students as potential vehicles for bringing the latest research on childhood literacy to the real world and practitioners as helping students to frame their understanding of research and theory in authentic contexts. While we assumed that such an online community would be of interest and benefit to both students and practitioners, it was important to conduct a needs analysis with potential target users to hear from them what value they perceived they would get from participating in such a community. This is an important first-step in the design of any learning activity - if the proposed learning scenario does not meet target users' needs, it will not be successful. The "if you build it they will come" philosophy that characterized the design and development of online learning in its early years has been abandoned as educators and instructional designers have realized that identifying the target audience and their needs is crucial to the success of online learning.

Indeed, there are many potential benefits to online learning, including:

- Greater access to learning. We believed that an online community could facilitate learning opportunities among learners from a variety of stakeholder groups (i.e. students, librarians, early years practitioners) where normally such sharing and interaction may not be feasible.

- Better allocation of teaching resources. An online learning community could potentially house a variety of teaching resources for users to access when needed. 
One central repository for materials would reduce the time needed to for searching and potentially point stakeholders to resources from other community members that they may not have access to within their own community of practice.

- The ability to share learning content. An online community may have learning content and materials to be shared among the stakeholder groups in a way that was not possible without technology.

- The potential for facilitating deeper learning among users. The ability to make connections both within and outside one's own community of practice is essential. We envisioned that our online community could potentially allow learners to engage in learning practices until skills, knowledge or expertise are learned or developed, some of which may reside outside their traditional scope of knowledge and experience (for instance, to apply research to practice).

- Social component to learning which can be facilitated among communities of learners, often separated by geographic location. The online community will enable members to share with other practitioners and researchers their experiences with early child literacy. (Rossiter Consulting, 2006).

The class situation that formed the basis for the present study was a third-year Psychology course in Child Development, with a focus on early communication or, as its title suggests, "How Babies Communicate with the World." The class enrollment of approximately 60 students was divided into three sections of about 20 students each. One 
weekly lecture was delivered to the full class and remaining class time was spent within the smaller sections. In each section, student groups of 4-5 members were able to choose from among assigned topics in the area of early communication as the focus for their major course projects. These topics (e.g., Why talk to your fetus? Why do we sing to infants? How do hearing impaired infants communicate?) were the same across sections. Experts in the field who specialize in particular topics of interest were invited as guest lecturers for the course and for discussions with small groups of students who were working on those topics.

\section{Benefits of Online Community for both Students and Practitioners}

Because of our students' positive response to the opportunities for discussion of their topics with known experts, it was felt that ongoing discussions with community-based early years practitioners might also add value to the course experience. The value to students of opportunities to apply their learning in authentic contexts, provided through discussions with practitioners, also has been observed in the literature (Brown \& Campione, 1994). Barnett, Harwood, Keating and Saam (2002), for example, observed the implementation of an Inquiry Learning Forum that was designed to support preservice elementary school teachers in discussing their beliefs about inquiry-based teaching. In-service teachers participated in the discussion groups, and the majority of students commented that the participation of the in-service teachers helped make the discussions understood within the context of a real classroom, rather than the discussion being viewed only as a class assignment. 
There are also advantages for practitioners who participate in online learning communities with students. In particular, communities of practice, regardless of whether they are virtual or face-to-face, can benefit from interactions not only among their own members, but also by interacting with other, related communities. Riel and Polin (2004) have described communities as relatively healthy vs. dysfunctional, much in the same way as family or other relationships are, in part, defined by their ability to accommodate change or variation. They and others (e.g., Lave \& Wenger, 1991; Wenger, 1998) have noted that communities tend to develop cultural norms based on accepted roles, a sense of shared purpose, behavioural expectations, communication patterns, rules, and activity structures associated with their practice. The exchange of information and perspectives with other groups who are engaged in tangentially related practices helps a community of practice to develop relationships in healthy ways because it provides opportunities to balance the rigidity and limitations that come with reified cultural knowledge and activity structures (Lave \& Wenger, 1991; Riel \& Polin, 2004; Wenger, 1998).

In our study, we anticipated that there could be several advantages for community members interested in child literacy participating in discussions with university students. These included opportunities:

- For working practitioners to connect with other practitioners to discuss issues and evidence of relevance to their work; 
- For parents or others working with children to connect with students who can provide feedback on practical questions that is guided by current research;

- For professionals to connect with students who might help articulate and translate practical issues and problems into research questions and designs; and

- For professionals to make contacts with university faculty who can provide access to research findings, ongoing projects, and literature of interest to them and their organizations.

\section{Focus Groups to Identify Needs and Interests of Community Partners}

To gain first-hand input regarding the needs and interests of community members we believed would be interested in participating in a discussion forum about child literacy, we ran a number of focus groups. We saw these focus groups as a way to explore with the community members what general topics in the area of childhood literacy might be valuable to address in a discussion forum with students.

Focus groups of 10-12 participants were conducted at various locations across southwestern Ontario. Participants were recruited from several groups we believed would be interested in participating in an online community to learn about 'How and why to Read with Young Children'. These included parents, early literacy specialists from Ontario Early Years Centers, undergraduate and graduate students in Child Development, educators, and librarians. The different groups were asked to participate in the focus group discussions to provide different perspectives on the idea of this type of online 
community. For example, parents of children entering junior kindergarten were targeted because of school readiness and literacy issues faced by parents of young children. Early literacy specialists were included because of their interest and knowledge about early childhood development and their potential interest in facilitated online information sharing and access to learning resources. Librarians working in the area of child literacy were seen as bringing expertise in searching published literature as well as their interest in children and child development. Similarly, it was felt that educators specializing in literacy and early years teaching might see value in interacting with university students, who would bring research perspectives and ideas to the discussion. Senior graduate students in developmental psychology who had studied child literacy were asked to provide their perspectives on the viability and potential benefits of a community-student discussion forum.

Each group was conducted exclusively with members of a homogeneous community group or affiliation. For instance, one group involved community members who were participating strictly as parents, another involved only librarians, while another involved only early literacy specialists, and so forth.

\section{Planning and Implementation of Focus Groups}

The same university mediator guided all focus groups. Identified members of each focus group were contacted approximately one week before the scheduled session so that the purpose and procedures of the group discussions could be explained. Participants were 
asked to come to the focus group prepared to say a few words about their most exciting experience being part of a learning community working with children.

The mediator began each session by asking two to three participants to share their most exciting experiences. The sharing of positive experiences was used as an Appreciative Inquiry technique (Mohr \& Magruder Watkins, 2001), which is intended to facilitate a positive mind-set in participants at the beginning of the session. Each group was then asked a series of four open-ended questions:

1. Would you be interested in becoming part of an online community involving people with a variety of experience and expertise, to learn about, share information on, and discuss child literacy? For what reasons would you be interested or not interested?

2. What topics would you be interested in learning about and discussing as part of an online community?

3. In what format would you like to communicate, learn, and share information? These might be formats such as online discussion boards with posted materials that one can read and respond to at any time (sometimes referred to as "asynchronous" discussion forums), online chat rooms, or face-to-face, "live" events.

4. Can you think of other groups of people you know of who would be interested in participating in this online community?

The mediator used probes to expand on issues, clarify questions, or clarify a respondent's meaning. Each focus group lasted approximately one hour and was transcribed and 
videotaped to ensure the accuracy of panelist responses. Refreshments were provided as an appreciation for the group members' participation.

\section{Results from the Focus Groups}

Participant responses from each group were recorded by an observer and then paraphrased in written form. To highlight similarities and differences in responses across groups, responses to each question are presented separately. These results are presented in Appendix A.

The first and third questions both focused on participants' reactions to the notion of an online community or discussion forum, and the format that such communications might take. All groups indicated that they would be interested in participating in an online community, although time constraints were frequently cited as a potential drawback. The groups agreed that being able to connect with others to discuss problems and issues of shared interest would be beneficial and rewarding. They also seemed to like the idea of being able to access resources such as in a searchable database, which could provide information and answers to questions and problems they face in their work.

All of the groups indicated that face-to-face interaction remains important, especially when connecting with parents, who may not necessarily have the skills or other resources to be able to access the internet. However, they all agreed that online community discussions would be useful and, in many cases, preferred. Many of the benefits of 
online learning identified at the outset of the paper were reasons cited by participants for preferring online education. Advantages that were mentioned included the ability to think and reflect before posting to a discussion, in an online environment, and to connect with people who can offer perspectives they normally do not encounter - such as real-world perspectives that parents can offer university students and the perspectives of colleagues that librarians may not typically hear (greater access to learning, sharing learning content, deeper learning and the social component to learning are all indicated here). Many participants felt that a combination of asynchronous discussions and live, scheduled events, such as online guest lectures or chat sessions with experts on a specific topic would optimize the usefulness of an online community forum.

In response to the second question, a wide variety of topics were identified as being of interest to these participants, as a focus for online community discussions. In the case of both the Librarians and Early Years Specialists, topics of interest typically were related to their day-to-day work activities, including specific kinds of challenges in fostering literacy with various populations of parents and children, and also ways of reaching out to parents in order to help them promote literacy in their children. For instance, gender was a key concern for both Librarians and Early Years Specialists. They noted wanting more information about how to engage boys with books as well as how to engage fathers in reading to their children. For Librarians, another key area of interest was how to engage immigrant children and their parents as well as how to design programs with an ESL component. On the other hand, undergraduate and graduate students were interested 
in discussing ways to promote literacy with various target groups, but they also appeared to be interested in research questions that could be defined or addressed in an online community. Additionally, they wanted to gain parents' views and practical knowledge about children's development.

These differences in the focus taken by undergraduate and graduate students compared to that of Librarians and Early Years Specialists is notable but perhaps not surprising given the context in which these two groups answered the questions. Given the strong research focus of both universities where the undergraduate and graduate student groups were from (University of Waterloo and McMaster University respectively), it is logical that the students would have this focus in mind when considering the value of an online learning community to them. Similarly, one might expect that, as students, they could potentially have less experience with either children or parents than practitioners, so gaining exposure and insight into this aspect of child development would be especially valuable to these groups.

When asked about other potential groups of people who might be interested in participating in an online learning community or discussion forum, a variety of groups were identified. Students in areas such as early childhood education, child development and teacher education were identified by all of the groups. Other identified groups included members of community service occupational groups, such as physicians, librarians, home and centre-based child care providers, tutors, multi-cultural community 
service workers, home school providers [e.g., organized home schooling parents], attendance counselors and other school board staff who deal with families, and even children and adolescents themselves. Judging from this wide range of suggested candidate groups, it appears that participants perceived value in exchanging information and perspectives with a variety of people who are interested in child literacy.

\section{Conclusions and Future Directions}

The focus groups we conducted involved community members whose work promotes childhood literacy and university students who plan to work with young children and/or research issues related to early literacy. We received a very positive response to the idea of participating in an online discussion forum related to these issues.

A variety of communication formats were discussed as potentially valuable in making the connections that can facilitate and support learning communities. While face-to-face sessions were still considered an important aspect of relationship-building where it is feasible, a range of online communication formats were also considered valuable in their own right. Asynchronous discussion forums, web-based resource tools, and scheduled online "live" chats involving topic experts were noted as an excellent combination of formats to meet the needs of different participants.

Value was also seen in making it possible for a variety of perspectives to be represented in an online community. Community professionals and students all agreed that 
discussing child literacy issues with others who bring disparate points of view would help them to build knowledge and understanding in key ways. Community workers appreciate the value of engaging with students, parents, and other professionals in order to expand the scope of their thinking and their ability to facilitate the growth of literacy. Students consider the real-world knowledge and perspectives to be extremely useful in helping them to ground their developing knowledge and their inquiry about child literacy. In short, all of the focus group participants felt that their early literacy work could benefit from connecting to others who had different experience and expertise than their own and that this could potentially be facilitated in an online community.

The benefits, for both students and community practitioners, of participating in an online discussion forum around childhood literacy emerged clearly in these focus group discussions. The contributions to such a learning community are different, depending on group members' affiliations: Students act as conduits of current research findings to practitioners in the community, while professionals are able to ground university research questions in real-world issues, problems and contexts.

How can you make use of these ideas in your own practice in the field of child literacy? If you are working in a local organization that deals with literacy issues, the potential for establishing a learning community may be realized through contacts with post-secondary institutions in your area. For example, a college or university in the vicinity likely has programs in which students would be interested in discussing childhood literacy with 
community practitioners. These could be college or university professional programs for teacher preparation, child care or early childhood education, or in more theoretical areas such as Developmental or Clinical Psychology. 


\section{References}

Barnett, M., Harwood, W., Keating, T., \& Saam, J. (2002). Using emerging technologies to help bridge the gap between university theory and classroom practice: Challenges and successes. School Science and Mathematics, 102(6), 299-314.

Brown, A. L. \& Campione, J.C. (1994). Guided discovery in a community of learners. In K. McGilly (Ed.), Classroom lessons: Integrating cognitive theory and classroom practice (pp.229-270). Cambridge, MA: MIT Press/Bradford Books.

Lave, J. \& Wenger, E. (1991). Situated learning: Legitimate peripheral participation. New York: Cambridge University Press.

Mohr, B.J. and Magruder Watkins, J. (2001). Appreciative inquiry: Change at the speed of imagination. Jossey Bass/Pfeiffer.

Riel, M. \& Polin, L. (2004). Online learning communities: Common ground and critical differences in designing technical environments. In S.A Barab, R. Kling \& J.H. Gray (Eds.), Designing for virtual communities in the service of learning (pp. 16-50). New York: Cambridge University Press.

Rossiter Consulting (2006). State of the Field Review in E-Learning: Final Report. Ottawa: Canadian Council on Learning. Accessed October 26, 2006

Wenger, E. (1998). Communities of practice: Learning, meaning, and identity. New York: Cambridge University Press. 


\section{APPENDIX A: Responses of Focus Groups to each of Four Questions}

\section{Question 1: Would you be interested in becoming part of an online community? Why or why not?}

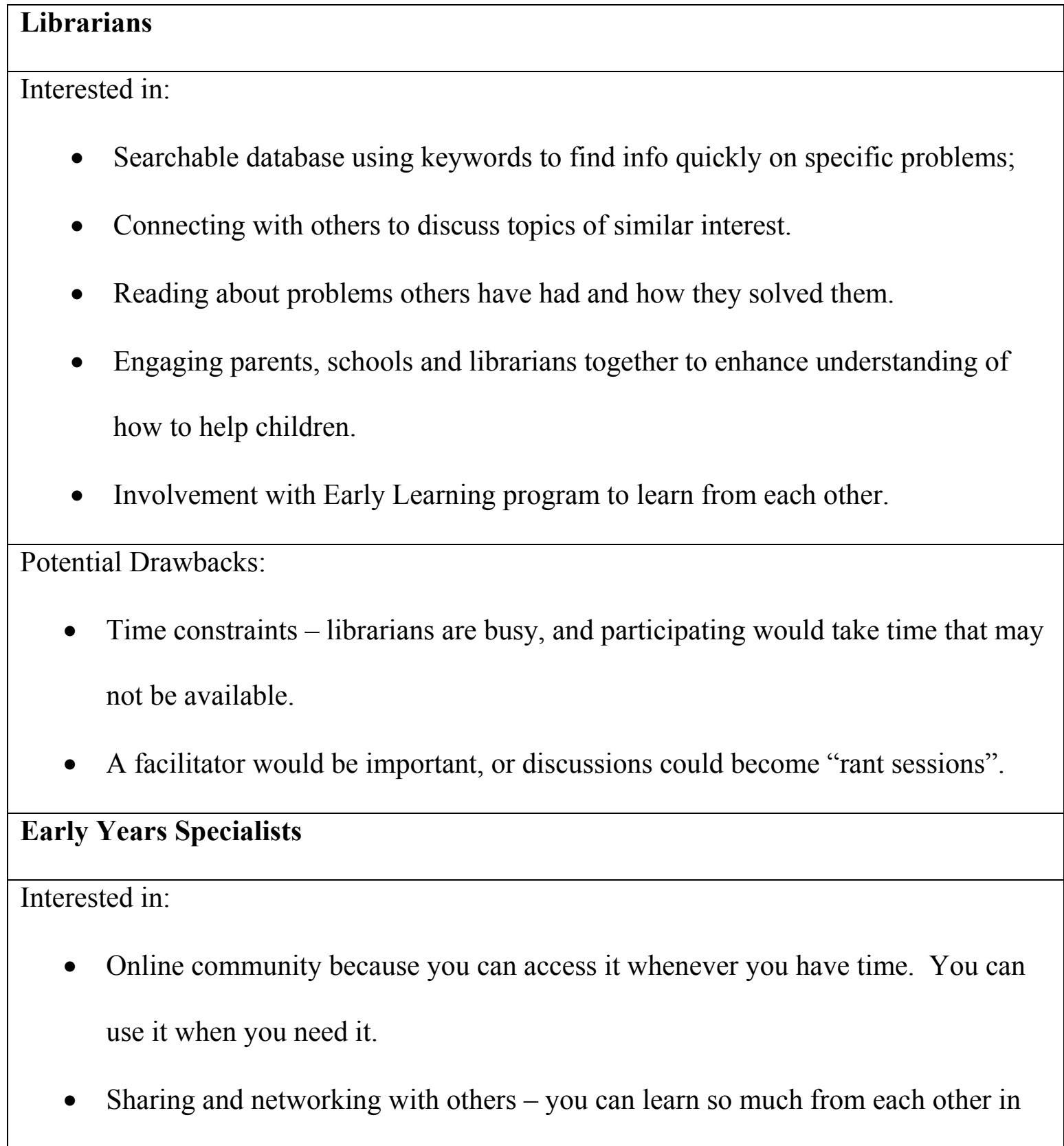




\begin{abstract}
just a couple of hours together.
Potential Drawbacks:

- Time is definitely an issue.

- Parents [whom we communicate with a lot] often don't have computer access or skills. They would usually prefer face-to-face.

- Computer can supplement, but often you need people actually being together [even for us] -sometimes you need the real person there, for that immediate interaction.
\end{abstract}

\title{
Graduate Students
}

Interested in:

- General discussion with others to hear other points of view, to gain new ideas about where to go with my research.

- Discussions that could serve as an information resource for me, so I can pass on useful information to parents.

- Discussion about real-world problems and issues, which will help us to see the relevance of our research, and to consider questions of relevance.

- Preparing for our future role as teachers and/or parents by learning community perspectives as well as research.

Potential Drawbacks:

- Time constraints make it unlikely that students will participate unless they can earn credit. 


\section{Undergraduate Students}

Interested in:

- A group with mixed backgrounds - different experiences, ranging from professional to non-professional.

- Real-world applications brought by people from the community - researchers can get too focused on the lab.

- I plan to go to teacher's college next year, so it will be important to be involved in this kind of setting.

- An online community, since most students are already on the computer all the time - they wouldn't have to attend meetings where they might talk about topics you aren't interested in.

- Discussing with experts, where you can find answers, info for research projects.

Potential Drawbacks:

- None identified. 
Question 2: What topics would you be interested in learning about and discussing as part of an online community?

\section{Librarians}

Topics:

- Gender issues

- How to motivate kids to read

- What to do when there's a challenge in getting a kid to read

- The experience of immigrant children and parents - what others are doing(e.g., how they deal with language, things that may be offensive to other cultures, or when English is not the parents' first language)

- Reading to children who are hesitant to participate

\section{Early Years Specialists}

Topics:

- Boys - how to get boys to like books [they are more active], motivate them to read, differences in their learning

- School readiness issues - current info

- Pre-school parents want to know if their kids are ready, how they can help them to be ready and what will be expected when they get to school

- Bringing fathers [and other male role models] in and motivating them - helping them realize how important their role is

- Other ways to encourage literacy besides reading - music, rhyming, nursery 


\begin{tabular}{|l|}
\hline - - Giving parents examples of how reading can be fun instead of boring, or a chore \\
- Helping parents to see how things they are already doing may be helping to ready \\
their kids for reading - once they realize, they will do more of it! \\
Graduate Students \\
Topics: \\
- Getting info from parents about what babies are like at different stages \\
- Identifying some of the challenges and the success strategies re: Child Literacy \\
- Getting children interested in reading at various reading levels \\
- Potential connections between kids not liking to read and some other factors - \\
- getting quick feedback from what parents have noticed - current predisposition to \\
- things, cognitive style, etc. \\
- Hhat if they brought questions in from things they say on TV, etc., to check out \\
- the validity of claims they hear, etc? \\
Undergraduate Students
\end{tabular}


needs, and parental influence from teaching them to read right from the start

- Does the early book gift program work, especially with children with special needs?

- Children with behavioural issues - how to foster reading with them

- Technology and how it impacts reading - Wal-Mart has these tech games that help kids learn how to pronounce words, etc. and computer games.

Question 3: In what format would you like to communicate, learn, and share information?

\section{Librarians}

Format Preferences:

- Getting away from the computer [because we sit in front of it all day] would help - so face-to-face would be good;

- The computer to act as facilitator of personal connections, like schools and libraries; providing up-to-date contact info;

- Print info is good too so you can share it with parents who may not have internet access.

\section{Early Years Specialists}

Format Preferences:

- Visual - to be able to [learn things] when I can, in my home; 
- Hands-on, a “do-er;" playing a jeopardy game or a shopping mall approach;

- Tours of Associations of Childhood Educators - I enjoy that type of thing; also reading, looking on the computer [visual learner];

- Working at my own pace, where and when I can; tangents are important so discussing with others is really worthwhile. Both ways are important and complimentary;

- Visual and practical in combination;

- Being online is good because you can print things off to read and/or copy later;

- A conference is really great to get new info "right off the plate;"

- Being with people - their emotions and excitement gets lost when just reading - I find that the computer or reading is great for just facts, but beyond that I like to hear it "live". For parents too - they get inspired at workshops and would not if they just read about things they can do with their children;

- At a meeting, what happens at the breaks is priceless - you get valuable info from other participants. Getting perspectives from others adds so much to what you've heard in a formal talk. The networking and brainstorming is so valuable.

\section{Graduate Students}

Format Preferences:

- Face-to-face seems more rewarding, but realistically, time constraints make it difficult;

- Online you really have time to think about issues, reflect before inputting ideas; 
- On the other hand, if you do it right away you'll definitely do it. If you post a question and then go back the next day and again, and there's no answer, you may never go back to the site.

- If there is an online forum, the issue of presence is a real one - there are other people there and everyone needs to realize that.

- [Referring to a fitness and diet community example] - They had timed live chats with a trainer, which provided that structure. That would be really good.

\section{Undergraduate Students}

Format Preferences:

- It depends on who it is - I get nervous talking to profs, so if there were researchers and professionals, I would prefer the internet, rather than in the classroom;

- Asynchronous is more like email - you can go away for a couple of days and think about it. The chat is fun, but you have to think faster - they're different.

- I like the way UW-ACE works now [our online course management system] we can get together sometimes for chat, but also can post things to the discussion - so I like both of these.

- With online, you can draw from a wider base, from all over the world - using the same chat line or discussion board. If [a live event is] in the same city, you won't be able to draw from the same resources.

- You could post problems and the experts could read it and give suggestions, or 
you could have a guest speaker, etc.

- Variety is great to meet the needs of different people: You could have an expert there to give advice, you could have a chat room there, posting of different articles, etc. Like on ACE, there are different kinds of things there, all in one place.

- You could also have other mediums, like a classroom setting - you could have a guest speaker in different cities each month, then post the talks online afterwards that others could watch online.

- A lot of people have similar issues, so you could have people call in and ask questions; or different ideas on various topics that others would be interested in.

- I've been part of a few forums where people post a topic or question and you end up hearing their life experiences, about volunteer experiences etc. - and it motivates you to do things like that....

- Online is convenient for us because we've grown up with it but it doesn't mean we prefer it - we can learn that way but it's easier to sit in the classroom ... partly because it's at a set time, but also you can ask questions or hear others ask questions.

- The classroom is the best way to learn, you get immediate feedback. Also, the resources provided in either format are important - books, online resources, videos, etc.

- Even with a large class, I still prefer to be able to ask the prof questions and get 
immediate answers and feedback.

- I've done distance courses and they are always isolating, no sense of community. You don't get to know others in the class.

- Even when you go back to ACE [the online course environment used at this university] after meeting people face to face, it still isn't the same kind of relationship - but you could develop it, it would just take longer.

Question 4: Can you think of other groups of people you know of who would be interested in participating in this online community?

\section{Librarians}

Groups who would be Interested:

- The learner audience is going to be very different if it's parents of small children vs. adolescents, vs. targeting high schools, vs. targeting librarians or other community groups. The content and theory vs. practice focus would vary a lot.

- The ability to critically assess information of very different kinds, is what librarians can provide and help others with.

- We can only reach those who come through our door - What about other groups, like health workers, Children's Aid Society, etc.?

- What about multi-cultural family organizations like First Families, who might reach out to those families? 
- Books for babies, home visits through that...

- ECE faculties and programs

- Tutors - they have organizations which may be good to include

- Attendance councilors, and people who work at the school boards, they are very connected with the families of students.

- Initiatives that work best usually build on existing infrastructure - like the ones that schools use to pass from older siblings to younger ones as a way to reach them. TVNLP is one example.

\section{Early Years Specialists}

Groups who would be Interested:

- Sponsorships for people in the community, where we're trying to bring about an understanding of what we do and what we're trying to accomplish - they might support us even more.

- ECE students - it's the kind of thing they buy into anyway, it would fit their needs in terms of time and flexibility, and it's relevant.

- Library staff who are doing neat programs with kids

- Organizations for child literacy in the community

- Home child care providers

- Associations of home schooling providers [e.g., The Ontario Federation of Teaching Parents]

- Doctors, dealing with parents who are struggling with particular problems. 


\begin{abstract}
Graduate Students
Groups who would be Interested:

- Maybe children themselves;

- Publishers;

- Older teenagers, who could give ideas about strategies that worked or didn't work for them;

- Students I've met who had reading problems as kids, and had varying experiences with the way they were treated;

- If it's online, you might get personal experiences from children themselves, who like the anonymity of the internet, rather that speaking to their teacher. It would be interesting to hear kids themselves - their stories, and how they got this far with reading problems etc.
\end{abstract}

\title{
Undergraduate Students
}

Groups who would be Interested:

- Parents of children with special needs: the first thing I would want is to find others who are in a similar situation. Really useful tool, to share ideas; useful suggestions, support.

- Many who would take the initiative to go online may not be the ones that could benefit most - they may not have access or the skills or motivation to go online. But they may be the kids with disabilities, and they need the info - maybe going into schools or community organizations - internet isn't always the best way. 
- I volunteered at a day care center and found that when parents came to pick up the kids they would have to go home and get dinner etc. so they didn't have time to go out places - it should be brought to where they are [e.g., baby sit the kids while they participate $\mathrm{n}$ a group session on some topic].

- A child care centre I volunteered at had a lounge where parents could sit and relax when they picked up the kids; there was a nurse there and info available on various things.

- Different levels of skill on the internet and different ways to use it are important. Local level providing phone numbers etc. and international level to find a broader base of info on a subject.

- Undergrads are a good target learner group because we are in a research course, so we need a lot of resources and we work in groups etc.

- Maybe not all undergrads, just those in teaching-related fields [psychology, child development etc.]

- Potential parents, potential teachers. 